\title{
A Synthesis of Six Recent Studies on Numerosity Abilities in an Ant
}

\author{
Marie-Claire Cammaerts (Corresponding Author) \\ Independent researcher, retired from the Biology of Organisms Department, University of \\ Brussels, Belgium. E-mail: mccammaerts@gmail.com \\ Roger Cammaerts \\ Independent researcher, retired from the Natural and Agricultural Environmental Studies \\ Department (DEMNA) of the Walloon Region, Belgium. E-mail: rogercammaerts@ gmail.com
}

Received: November 12, 2021 Accepted: December 15, 2021 Published: December 20, 2021

doi:10.5296/jbls.v13i1.19346 URL: https://doi.org/10.5296/jbls.v13i1.19346

\begin{abstract}
Working on the numerosity ability of the ant Myrmica sabuleti, we have already summarized for the readers' convenience our previous papers in two successive publications. Since that time, we have produced six more papers on the subject, and we thought it was time to present a summary of them. These studies deal with the ants' ability in expecting the following element in an arithmetic or a geometric sequence, as well as with the required similarity between visual cues and the maximum horizontal and vertical distance between such cues enabling the ants to mentally add them up. The experimental methods that were used in these studies are here only briefly reported and their most important results are concisely related, as the extended information can be found in these six papers here summarized. We present novel tables and figures for illustrating this synthesis.
\end{abstract}

Keywords: adding, cognition, expectative behavior, Myrmica sabuleti, operant conditioning

\section{Introduction}

We have previously published sixteen research works on the numerosity capability of the workers of the ant Myrmica sabuleti Meinert, 1861, and for the readers' convenience we moreover summarized them in two papers. A first one synthesized our nine first works on the subject (Cammaerts \& Cammaerts, 2020d) and a second one the seven following works (Cammaerts \& Cammaerts, 2020e). Among the subjects examined in these sixteen studies on the workers of $M$. sabuleti, let us cite their acquisition of the notion of zero through experiences, their natively possession of a left to right oriented number line, their capability of adding numbers of elements, and their capability of acquiring symbolisms for numbers 
including the zero and of using this symbolism for adding up numbers. In the meantime, other research showed that $M$. sabuleti workers can expect future occurrences on the basis of previous experienced events (Cammaerts \& Cammaerts, 2016a, b). More recently, we published six more studies on the $M$. sabuleti numerosity ability and, for the readers' convenience, we here synthesize them. These works deal successively with the ants' expectation of the following and even the exact next element in an arithmetic and a geometric sequence, then with the required similarity, horizontal and vertical proximity of visual cues enabling the ants to add them up. Before presenting these last studies, we here below briefly report what is known as for these last topics in animal species other than M. sabuleti.

Several animals are capable of prospective thinking. As examples, scrub jays can anticipate their need of food in response to a learned situation and independently of their present need (Raby et al., 2007; Correia et al., 2007). Great apes (bonobos, chimpanzees, and orangutans) can save tools for a future use (Osvath \& Osvath, 2008). Kea parrots (Nestor notabilis) can also wait in favor of a preferred reward (Schwing et al., 2017). Such cognitive ability leans on episodic memory (Clayton \& Dickinson, 1998). In mammals, the hippocampus has been shown to play an essential role for ensuring episodic memory (Suddendorf et al., 2009). This fore thinking requires memorizing past experienced events as well as, at the same time, their localization in the running time (Jozet-Alves, 2012). Concerning the invertebrates, let us cite, among others, the ability of bees trained to learn larger/smaller size rules to thereafter extrapolate such learned rules to novel stimulus sizes (Howard et al., 2017). Learning a sequence of numbers or of other elements has been observed in several animal species. See, for instance, the review of Kershenbaum et al. (2014) on acoustic communication and the work on sequential learning of visual patterns by honey bees (Collett et al., 1993). The ant Gigantiops destructor is also able to use sequential learning of the size of visual landmarks and to generalize the learned rules by interpolating the relative size of novel encountered landmarks (Beugnon \& Macquart, 2016). On the basis of such information and of what we know about the $M$ sabuleti workers' expectative behavior, we looked, in three successive works, if they present some numerosity expectation.

Concerning the adding ability of animals, this is acquired through three cognitive steps: discriminating amounts of elements, precisely assessing such amounts, and being able to add and subtract elements. Fishes and amphibians are at the first step (Agrillo et al., 2008; Rose, 2018). Birds and mammals can count elements (Hunt et al., 2008; Peperberg \& Gordon, 2005; Range et al., 2014: Woodruff \& Premack, 1981). Some of them can make additions and subtractions of elements (e.g. Garland \& Low, 2014; Rugani et al. 2009; Flombaum et al., 2005). Honeybees can learn to add or to subtract one element to or from 1 to 5 ones (Howard et al., 2019). Workers of the ant $M$. sabuleti can add elements when seeing them simultaneously, not when seeing them consecutively (Cammaerts \& Cammaerts, 2019a, b), but no further precision was known on the conditions required for them adding up cues. For increasing our knowledge on the subject, we examined, in three successive works, if $M$. sabuleti workers add only identical elements or also elements of different kinds, and what is the horizontal and vertical distance between two cues beyond which the ants no longer add the cues but act such as when they perceive them consecutively. 
We thus here relate our six last works on the numerosity ability of the workers of the ant $M$. sabuleti, largely shortening our experimental protocols and results since they are thoroughly described in these six papers (Cammaerts \& Cammaerts, 2021a, b, c, d, e, f).

\section{Material and Methods}

\subsection{Collection and Maintenance of Ants}

The ants were collected from Belgium, in the Aise valley (Ardenne), at Olloy-sur-Viroin (Ardenne), Marchin (Condroz) and Visé (Basse-Meuse). Each colony was maintained in 1 to 3 glass tubes half filled with water, deposited in a tray which served as foraging area and in which food (sugar water and pieces of Tenebrio molitor larvae) was regularly provided. The lighting equaled 110 lux while not working on ants, and about 330 lux while caring of or experimenting on them. Humidity was $c a 80 \%$, temperature $c a 20^{\circ} \mathrm{C}$ and the electromagnetic field $2 \mu \mathrm{Wm}^{2}$.

\subsection{Cues Presented to the Ants}

The visual cues used were colored or black shapes tied on the front face $(2 \mathrm{~cm} \times 2 \mathrm{~cm})$ of a stand build in strong white paper and provided with a duly folded base $(2 \mathrm{~cm} \mathrm{x} 0.5 \mathrm{~cm})$ to ensure their vertical maintenance. The cues differed according to the conducted study. For the first one, the stands bore 1 to 5 blue or yellow circles (diameter $=0.2 \mathrm{~cm})($ Cammaerts \& Cammaerts, 2021a). For the second study, the cues were 1 to 6 such circles (Cammaerts \& Cammaerts, 2021b). For the third work, they were 1 to 6 blue or yellow squares with an area of $1,2,4,8,16$, or $32 \mathrm{~mm}^{2}$ (Cammaerts \& Cammaerts, 2021c). For the fourth study, the cues were black squares, stars and triangles, or black, yellow and orange squares, or black parallelograms of different dimensions, or black squares differently located on the stand (Cammaerts \& Cammaerts, 2021d). In the fifth work, we used black squares, circles, triangles, vertical rectangles, horizontal rectangles, and stars located from each other at a horizontal distance of 3.5, 4.0, 4.5, 5.0, 5.5 or $6.0 \mathrm{~cm}$ (Cammaerts \& Cammaerts, 2021e). The sixth work used black circles, squares, triangles, vertically oriented rectangles, horizontally oriented rectangles, crosses, stars, and the letter ' $Z$ '. These six cues were either lowly located, at a height of $c a 3-5 \mathrm{~mm}$, or highly located, at a vertical distance of 1.5, 2.0, 2.5, 3.0, 3.5, 4.0, 4.5 or $5.0 \mathrm{~cm}$ above the lowly located cue (Cammaerts \& Cammaerts, 2021f).

\subsection{Ants' Training and Testing}

Globally, the ants were trained in their foraging area, the cues to memorize being set near the nest entrance and/or the food which served as rewards. They were tested in a separate tray in front of several cues which differed according to what we were studying. This can be seen in Figures 1 to 6.

During our first study, the ants were trained successively to $1,2,3$ and 4 blue cues, or successively to 5, 4, 3, and 2 yellow cues, and were then tested in front of 1 to 5 blue or yellow cues respectively (Cammaerts \& Cammaerts, 2021a). During our second study, the ants were trained successively to $1,2,3$ and 4 blue cues, or successively to $6,5,4$, and 3 yellow cues, and were then tested in front of 1 to 6 blue or yellow cues respectively 
(Cammaerts \& Cammaerts, 2021b). During our third study, the ants were trained to blue squares having successively an area of $1,2,4$ and $8 \mathrm{~mm}^{2}$, or to yellow squares having successively an area of 32,16, 8 , and $4 \mathrm{~mm}^{2}$. They were then tested in front of respectively blue or yellow squares having an area of 1 to $32 \mathrm{~mm}^{2}$ (Cammaerts \& Cammaerts, 2021c).

During our fourth study, the ants were trained to two cues having a different shape, color, size or location on a stand, and were then tested in front of, simultaneously, these two single cues, each on a distinct stand, and of their simultaneous presentation on a same stand, i.e. their addition (Cammaerts \& Cammaerts, 2021d). For making our fifth work, we trained the ants to two identical cues, presented each one on a stand, and being located at a horizontal distance equaling $3.5,4.0,4.5,5.0,5.5$ or $6.0 \mathrm{~cm}$. They were then tested in front of these two single cues, each on a distinct stand and, at the same time, of these two juxtaposed cues on the same stand, representing their addition (Cammaerts \& Cammaerts, 2021e). Our sixth work was made by training the ants to two identical cues presented each one on a stand, one of the cues being lowly located (at a height of 2-3 mm), the other one being more highly located, i.e. at a vertical distance of 1.5, 2.0, 2.5, 3.0, 3.5, 4.0, 4.5 and $5.0 \mathrm{~cm}$ from the lowly located cue. The ants were then tested in front of these two differently located cues, presented each one on a stand, and at the same time, in front of the two superimposed cues, i.e. presented together on a same stand (being thus added), their initial vertical distance being maintained (Cammaerts \& Cammaerts, 2021f).

\subsection{Presentation of the Results, Statistical Analysis}

A look at Tables 1 to 6 allows a better understanding of the present subsection. They summarize the results of our six last published works.

In these tables, we report (a) for the first three works, the conditioning scores reached by the trained ants, and the total numbers of ants sighted in front of the different cues presented during testing; (b) for the last three works, the total numbers of ants counted in front of the different cues presented during testing, for each three (fourth work) or each two (fifth and sixth works) used colonies.

Concerning the statistical analysis of the results, we report the results of non-parametric $\chi^{2}$ tests (Siegel \& Castellan, 1989) made (a) for the first three works, between the numbers of ants recorded during testing (the observed data) and those expected if the ants randomly visited the different presented cues (first and second works: one testing session; third work: two testing sessions); (b) for the last three works, between the numbers of ants recorded during testing in front of the single presented cues and in front of the added, juxtaposed or superimposed ones.

\section{Results}

\subsection{Expectation of a Following Number in an Arithmetic Sequence}

Numerical and statistical results are given in Table 1 and photos of the experiments can be seen in Figure 1. Two experiments were performed, a first one training the ants to, then testing them in front of an increasing arithmetic sequence, and a second one training the ants 
to, then testing them in front of a decreasing arithmetic sequence. The trained and the tested ants similarly responded, with equivalent strength, during these two experiments. They duly acquired the conducted conditionings, and, during the tests in front of the four elements of the sequence presented during training plus the following element, they essentially responded to the latter. They could thus anticipate, fore think, the following element of an increasing and a decreasing arithmetic sequence. However, the two performed experiments did not allow affirming that the ants expected exactly the just next, and not any following, element of the sequence. Also, these experiments did not allow knowing if ants present such an expectative behavior only in the presence of the sequence or also in its absence. Therefore, to solve these two uncertainties, a second and a third works on the subject were undertaken (see below).

Table 1. Examining if ants can expect the following number in an increasing or decreasing arithmetic sequence

Increasing arithmetic sequence

\begin{tabular}{|c|c|c|c|c|}
\hline \multicolumn{2}{|c|}{$\begin{array}{l}\mathrm{N}^{\circ} \text { of circles to and days at } \\
\text { which ants were conditioned }\end{array}$} & \multirow{2}{*}{$\begin{array}{c}\begin{array}{c}\text { Ants' conditioning } \\
\text { scores }\end{array} \\
82.75 \%\end{array}$} & \multicolumn{2}{|c|}{$\begin{array}{l}\text { At day 9, ants' responses to } 1,2,3,4,5 \text {, } \\
\text { simultaneously presented circles }\end{array}$} \\
\hline $1 v s 0$ & days 1,2 & & to $2: 4$ & to $3: 9$ \\
\hline $2 v s 0$ & days 3,4 & $72.22 \%$ & to $4: 14$ & to $5: 77$ \\
\hline $3 v s 0$ & days 5,6 & $86.46 \%$ & & \\
\hline $4 v s 0$ & days 7,8 & $91.30 \%$ & $\chi^{2}=119.22 \quad$ df $=4$ & $\mathrm{P}<0.001$ \\
\hline \multicolumn{5}{|c|}{ Decreasing arithmetic sequence } \\
\hline \multicolumn{2}{|c|}{$\begin{array}{l}\mathrm{N}^{\circ} \text { of circles to and days at } \\
\text { which ants were conditioned }\end{array}$} & $\begin{array}{l}\text { Ants' conditioning } \\
\text { scores }\end{array}$ & \multicolumn{2}{|c|}{$\begin{array}{l}\text { At day 9, ants' responses to } 1,2,3,4,5 \text {, } \\
\text { simultaneously presented circles }\end{array}$} \\
\hline 5 vs 0 & days 1,2 & $80.63 \%$ & to $1: 89$ to $2: 26$ & to $3: 11$ \\
\hline 4 vs 0 & days 3,4 & $70.45 \%$ & to $4: 4$ & to $5: 6$ \\
\hline 3 vs 0 & days 5,6 & $82.65 \%$ & & \\
\hline $2 v s 0$ & days 7,8 & $83.20 \%$ & $\chi^{2}=186.41$ & $\mathrm{P}<0.001$ \\
\hline
\end{tabular}

The ants could expect a following number of the sequence, but since they were tested in the presence of only the next number of the sequence, a subsequent work was performed to defining their skill. 

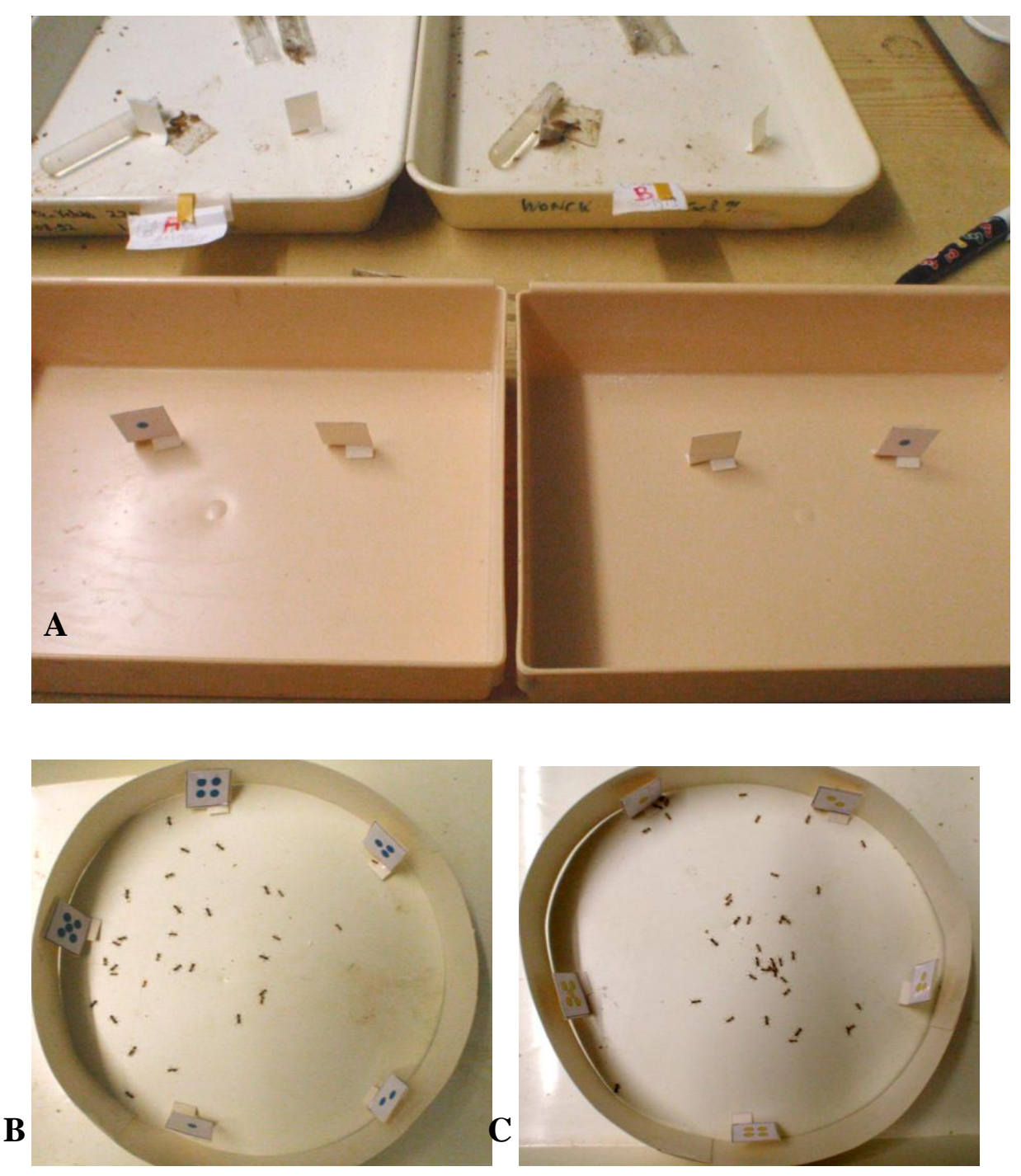

Figure 1. Some views of a first work on the ants' expectation of a following number in an arithmetic sequence. A: design of the ants' training (upper part) and testing (lower part). B: the ants trained to the increasing sequence ' 1 to 4 circles' went mostly towards the 5 circles. C: the ants trained to the decreasing sequence ' 5 to 2 circles' went mostly to the 1 circle.

\subsection{Correctly Incrementing the Last Number of an Arithmetic Sequence}

Numerical and statistical results are given in Table 2, and photos of the experiments are shown in Figure 2. Two experiments were conducted, one dealing with an increasing arithmetic sequence of numbers of elements, another with such a decreasing sequence. The results of these two experiments were in agreement with one another. Each time, the trained ants reached excellent scores, having thus learned and memorized the four successively presented numbers of elements. During the first experiment, when tested in front of the four (1 to 4) numbers of elements learned during training plus the two following ones $(5,6)$, the ants responded mostly to 5 elements, less to 6 elements and far less to 1 to 4 elements. During the second experiment, the ants tested in front of the four (6 to 3) elements presented during training plus the two following numbers $(2,1)$ of elements visited essentially the 2 elements, 
poorly the 1 element, and nearly not the 6 to 3 elements. All this was statistically significant. The ants have thus correctly incremented the last number of the sequence learned during their training, i.e. have added (first experiment) or subtracted (second experiment) one element to or from the last memorized number of elements. One of the problems stemming from the previous work (see above) was thus solved. It remained to examine if the ants presented such an exact expectative behavior either only in the presence of the sequence or also in its absence (the second problem stemming from the previous work). In addition, it remained to know if they also present such an expectative behavior faced with a geometric sequence. Our third work on the subject responded to these two questions (see below).

Table 2. Examining if ants can exactly increment the last number in an increasing or decreasing arithmetic sequence

Increasing arithmetic sequence

\begin{tabular}{|c|c|c|c|c|c|}
\hline \multicolumn{2}{|c|}{$\begin{array}{l}\mathrm{N}^{\circ} \text { of circles to and days at } \\
\text { which ants were conditioned }\end{array}$} & \multirow{2}{*}{$\begin{array}{c}\text { Ants' conditioning } \\
\text { scores } \\
81.0 \%\end{array}$} & \multicolumn{3}{|c|}{$\begin{array}{l}\text { At day } 9 \text {, ants' responses to } 1,2,3,4,5 \text {, } \\
6 \text { simultaneously presented circles }\end{array}$} \\
\hline 1 vs 0 & days 1,2 & & to $1: 1$ & to $2: 6$ & to $3: 4$ \\
\hline 2 vs 0 & days 3,4 & $74.8 \%$ & to $4: 5$ & to $5: 101$ & to $6: 15$ \\
\hline $3 v s 0$ & days 5,6 & $80.2 \%$ & & & \\
\hline 4 vs 0 & days 7,8 & $84.8 \%$ & $\chi^{2}=345.5$ & $\mathrm{df}=5$ & $\mathrm{P}<0.001$ \\
\hline \multicolumn{6}{|c|}{ Decreasing arithmetic sequence } \\
\hline \multicolumn{2}{|c|}{$\begin{array}{l}\mathrm{N}^{\circ} \text { of circles to and days at } \\
\text { which ants were conditioned }\end{array}$} & $\begin{array}{l}\text { Ants' conditioning } \\
\text { scores }\end{array}$ & \multicolumn{3}{|c|}{$\begin{array}{l}\text { At day 9, ants' responses to } 1,2,3,4,5 \text {, } \\
6 \text { simultaneously presented circles }\end{array}$} \\
\hline $6 v s 0$ & days 1,2 & $91.6 \%$ & to $1: 17$ & to $2: 139$ & to $3: 4$ \\
\hline 5 vs 0 & days 3,4 & $80.9 \%$ & to $4: 1$ & to $5: 4$ & to $6: 6$ \\
\hline 4 vs 0 & days 5,6 & $86.6 \%$ & & & \\
\hline 3 vs 0 & days 7,8 & $88.8 \%$ & $\chi^{2}=519.5$ & $\mathrm{df}=5$ & $\mathrm{P}<0.001$ \\
\hline
\end{tabular}

The ants responded to the next and not to the still following number of each sequence. 


\section{Macrothink}
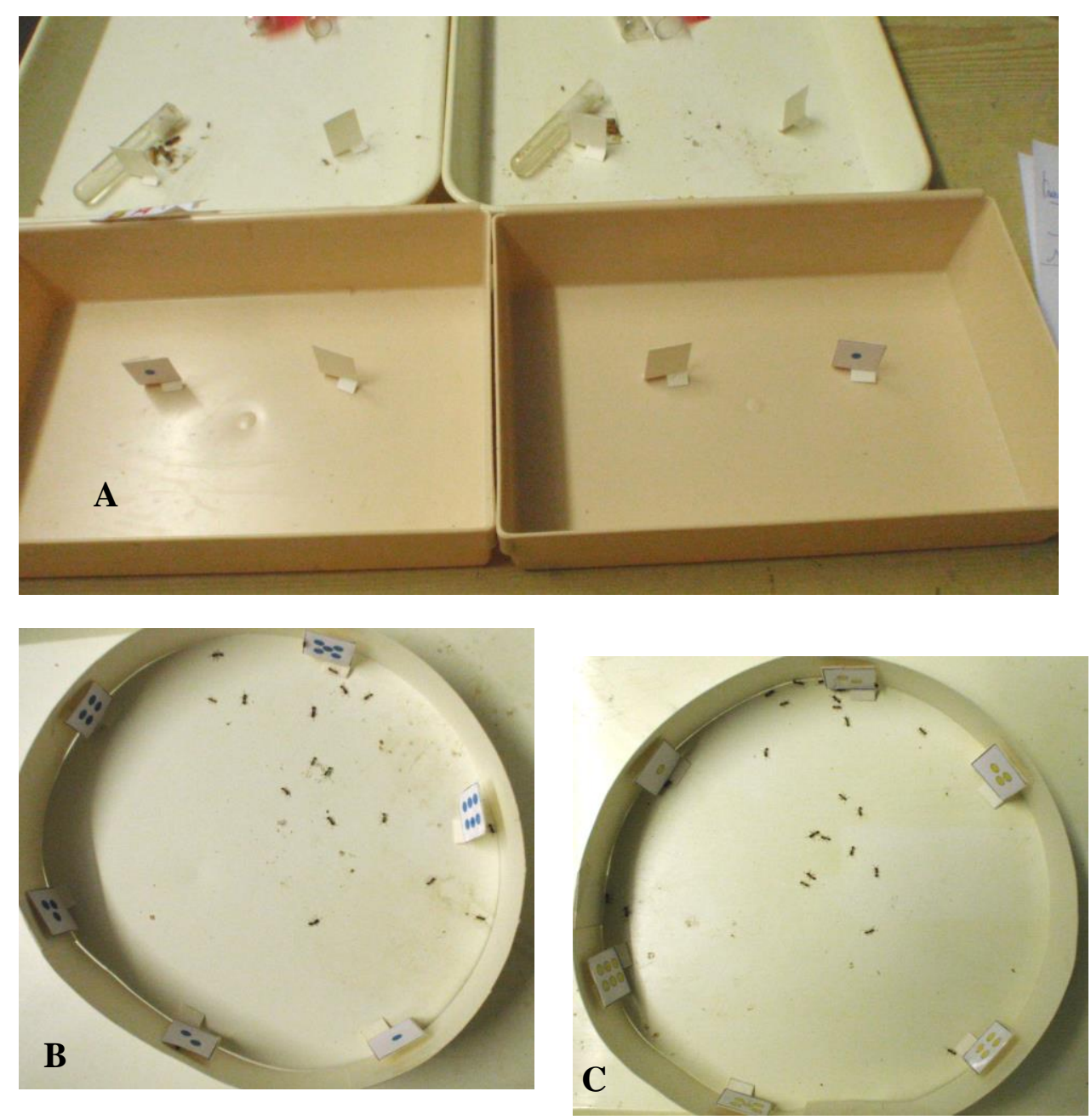

Figure 2. Some views of the second work on the ants' expectation of the exact following number of an arithmetic sequence. A: design of the ants' training (upper part) and testing (lower part). B: the ants trained to the increasing sequence ' 1 to 4 circles' went mostly to the 5 circles and not to the six ones. C: the ants trained to the decreasing sequence ' 6 to 3 circles' went mostly to the 2 circles and not to the 1 circle.

\subsection{Expectation of the Size of the Next Element in a Geometric Sequence}

Numerical results and statistical analysis are presented in Table 3 and photos of the experiments are shown in Figure 3. Two experiments were performed, one relative to an increasing geometric sequence of shapes, the other relative to such a decreasing sequence. Their results were fully in agreement with one another. Each time, the trained ants reached highly valuable conditioning scores. During the first experiment, when tested in front of the four shapes of increasing area $\left(1\right.$ to $8 \mathrm{~mm}^{2}$ ) plus the two following ones (areas of 16 and 32 $\mathrm{mm}^{2}$ ), these six shapes being presented in their correct sequential order, the ants went mostly to the shape having an area of $16 \mathrm{~mm}^{2}$ and far less to the other shapes, and this preference was statistically significant. They could thus correctly increment the last element of the learned increasing geometric sequence. When tested in front of the six shapes randomly located (i.e. in the absence of the sequence), the ants did not correctly respond, but randomly 
visited the six shapes. During the second experiment, the ants tested in front of the four shapes of decreasing area ( 32 to $4 \mathrm{~mm}^{2}$ ) seen during training plus the two following ones (areas of 2 and $1 \mathrm{~mm}^{2}$ ), these six shapes being randomly located, the ants randomly visited the six shapes, i.e. they did not increment the last element of the learned sequence. When tested in front of the same six shapes ranked in their correct decreasing order, i.e. in front of the sequence, the ants responded statistically far more to the shape having an area of $2 \mathrm{~mm}^{2}$ and very poorly to the other shapes. Thus, the ants could correctly increment the last element of the learned decreasing geometric sequence, but did so only in the presence of the sequence. This third work on the subject solved the previous emerged problems (see above).

Table 3. Examining if ants can expect the size of the following element in a geometric increasing or decreasing sequence

\begin{tabular}{|c|c|c|}
\hline $\begin{array}{l}\text { Area of the squares to } \\
\text { which and days at } \\
\text { which ants were trained }\end{array}$ & $\begin{array}{l}\text { Ants' } \\
\text { conditioning } \\
\text { scores }\end{array}$ & $\begin{array}{c}\text { At day } 9 \text {, ants' response to squares with an area of } 1 \\
\text { to } 32 \mathrm{~mm}^{2} \text { of surface simultaneously presented } \\
\text { either sequentially (s) or randomly (r) }\end{array}$ \\
\hline $1 \mathrm{~mm}^{2}$ days 1,2 & $91.43 \%$ & $\begin{array}{llllll}\text { (s) to } 1: 11 & 2: 6 & 4: 9 & 8: 6 & 16: 71 & 32: 5\end{array}$ \\
\hline $2 \mathrm{~mm}^{2}$ days 3,4 & $74.04 \%$ & $\chi^{2}=188.7, \mathrm{df}=5,<0.001 ; 16 v s 32: \chi^{2}=57.3, \mathrm{df}=1,<0.001$ \\
\hline $4 \mathrm{~mm}^{2}$ days 5,6 & $83.67 \%$ & (r) to $2: 13 \quad 1: 22 \quad 16: 21 \quad 4: 13 \quad 32: 16 \quad 8: 11$ \\
\hline $8 \mathrm{~mm}^{2}$ days 7,8 & $84.76 \%$ & $\chi^{2}=6.25, \mathrm{df}=5, \mathrm{P} \sim 0.25 ; 16 v s 32: \chi^{2}=0.67, \mathrm{df}=1, \sim 0.50$ \\
\hline $32 \mathrm{~mm}^{2}$ days 1,2 & $88.11 \%$ & $\begin{array}{llllll}\text { (s) to } 32: 10 & 16: 9 & 8: 17 & 4: 5 & 2: 95 & 1: 1\end{array}$ \\
\hline $16 \mathrm{~mm}^{2}$ days 3,4 & $70.16 \%$ & $\chi^{2}=279.4, \mathrm{df}=5,<0.001 ; 2 v s 1: \chi^{2}=92.04, \mathrm{df}=1,<0.001$ \\
\hline $8 \mathrm{~mm}^{2}$ days 5,6 & $87.78 \%$ & (r) to 1: $28 \quad 16: 12 \quad 4: 11 \quad 32: 15 \quad 2: 18 \quad 8: 11$ \\
\hline $4 \mathrm{~mm}^{2}$ days 7,8 & $87.10 \%$ & $\chi^{2}=13.59, \mathrm{df}=5, \mathrm{P}<0.025 ; 1 v s 2: \chi^{2}=2.16, \mathrm{df}=1, \sim 0.20$ \\
\hline
\end{tabular}

The ants correctly responded to the element having the next area value, but only in the presence of the sequence. 

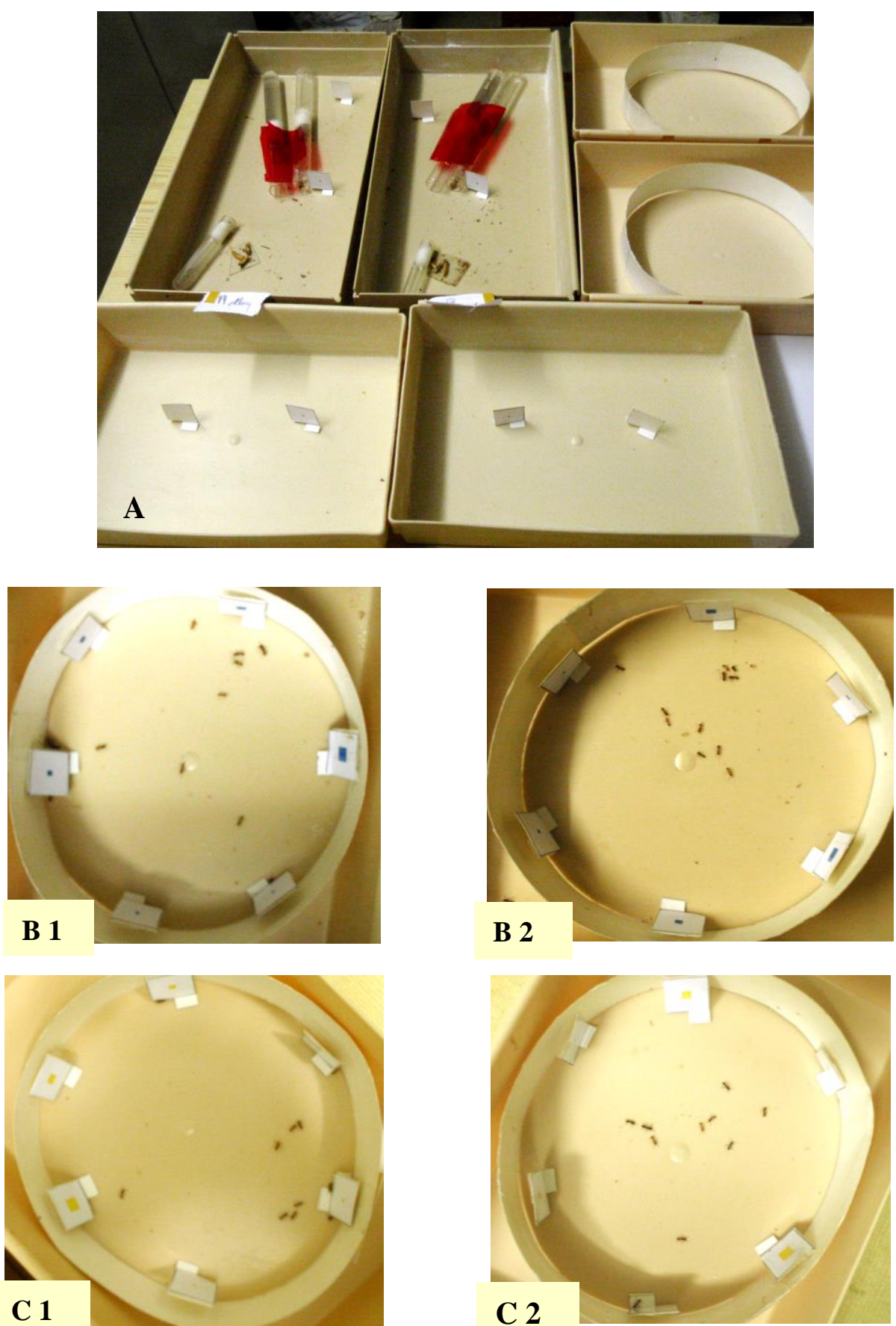

Figure 3. Some views of the experiments made to examine the ants' ability to expect the size of the next element in an increasing or a decreasing geometric sequence. A: experimental design used to train the ants (above, on the left), test them in the course of their training (below) and test them at day 9 (above, on the right). B: response of the ants to the elements of an increasing sequence. 1, orderly presented: the ants went mostly to the just next element of the sequence and not to the still following one; 2 , randomly presented: the ants did not go to the correct next element of the sequence. C: response of the ants to the elements of a decreasing sequence. 1 , orderly presented: they mostly visited the just next (= correct) element of the sequence; 2 , randomly presented: they did not go to the correct next element of the sequence. 


\subsection{Cues of Different Kinds Were Not Added}

Table 4. Examining if ants add elements of different shapes, colors, sizes or locations.

Difference between cues $\mathrm{n}^{\circ}$ of ants in front of each cue, of added ones and of a blank paper

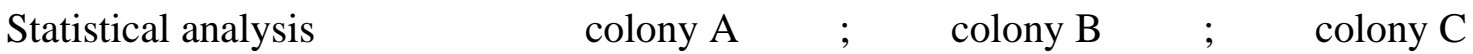

Different shape

each / added / blank; each / added / blank; each / added / blank

$99197 / 55 / 9 ; 166131 / 20$ / 8 ; $97204 / 17$ / 6

$\chi^{2}$ on $\mathrm{n}^{\circ}$ in front of one of

$$
\chi^{2}=247.11, \mathrm{df}=1, \mathrm{P}<0.001
$$

the cues $v s$ added cues

$\chi^{2}$ on $\mathrm{n}^{\circ}$ in front of the other cue $v s$ added cues

$$
\chi^{2}=310.26, \mathrm{df}=1, \mathrm{P}<0.001
$$

\section{Different color}

each / added / blank; each / added / blank; each / added / blank

$151173 / 27 / 10 ; 121112 / 3$ / $11 ; 168144 / 33$ / 3

$\chi^{2}$ on $\mathrm{n}^{\circ}$ in front of one of

$$
\chi^{2}=268.43, \mathrm{df}=1, \mathrm{P}<0.001
$$

the cues $v s$ added cues

$\chi^{2}$ on $\mathrm{n}^{\circ}$ in front of the other cue $v s$ added cues

$$
\chi^{2}=258.28, \mathrm{df}=1, \mathrm{P}<0.001
$$

\section{Different size}

each / added / blank; each / added / blank; each / added / blank

$165179 / 37$ / $8 ; 158186 / 29 / 5 ; 195168 / 12$ / 11

$\chi^{2}$ on $\mathrm{n}^{\circ}$ in front of one of

$$
\chi^{2}=320.18, \mathrm{df}=1, \mathrm{P}<0.001
$$

the cues $v s$ added cues

$\chi^{2}$ on $\mathrm{n}^{\circ}$ in front of the other cue $v s$ added cues

$$
\chi^{2}=338.83, \mathrm{df}=1, \mathrm{P}<0.001
$$

Different location

each / added / blank; each / added / blank; each / added / blank

1925 /213/ $18 ; 639$ /217/ 23 ; $36 \quad 33 / 233$ / 2

$\chi^{2}$ on sum of $n^{\circ}$ in front of

$$
\chi^{2}=310.63, \mathrm{df}=1, \mathrm{P}<0.002
$$

the single cues $v s \mathrm{n}^{\circ}$ in

front of added cues

The ants mentally added only cues which were differently located, and not those which differed by their shape, color or size. 

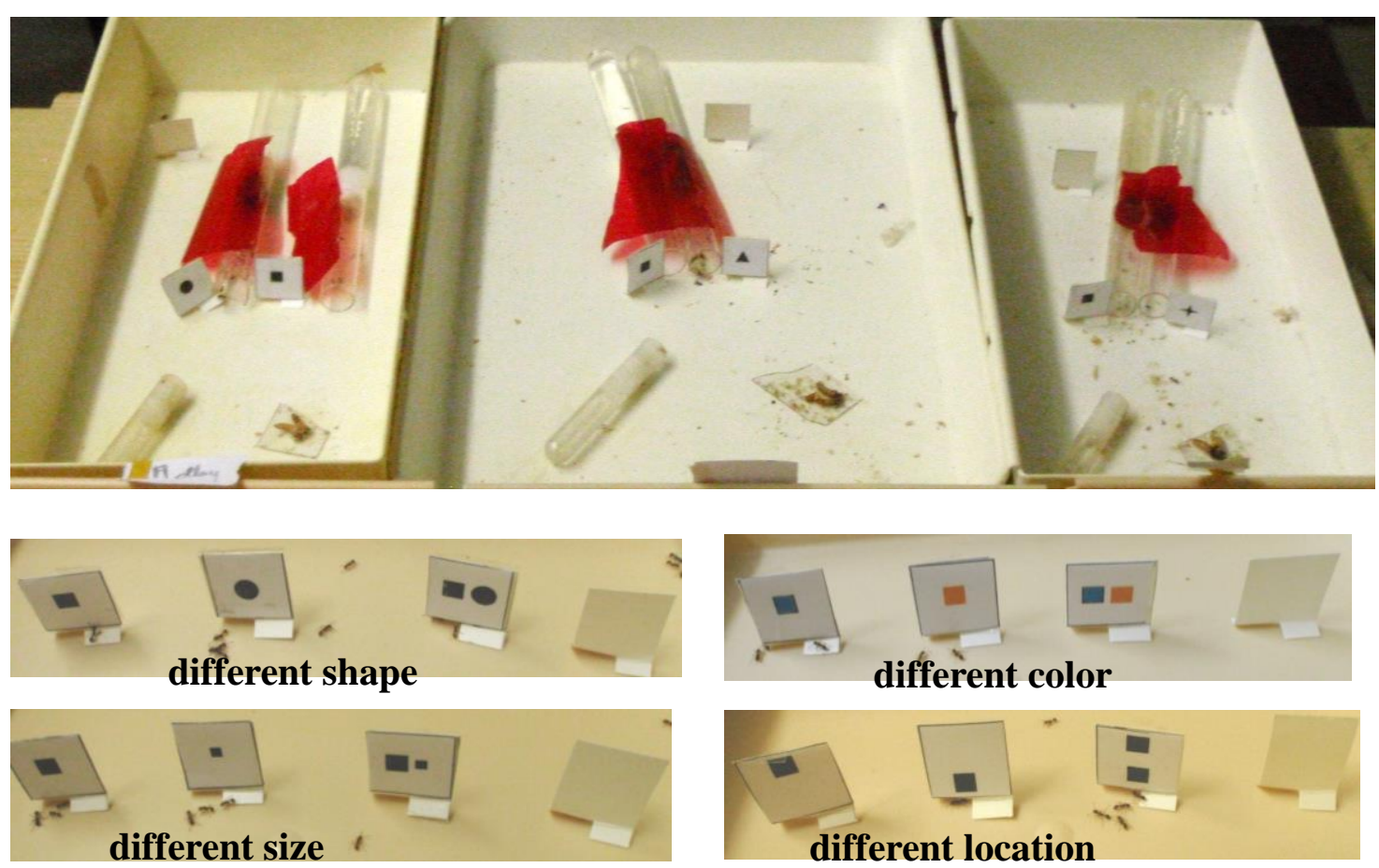

Figure 4. Views of the experiments made to know if ants add elements of different shapes, colors, sizes or locations. Upper photo: example of ants' training. Lower photos: four examples of ants' testing. The ants did not add elements of different shapes, colors or sizes, but well added elements differently located (= they reacted more to their addition).

Numerical results and statistical analysis are given in Table 4 and photos of the experiments can be seen in Figure 4. Four experiments have been performed. During the first one, the ants were trained to two cues of different shapes, i.e. to a black square and to a black circle, star or triangle. When tested in front of each of these two cues and of their juxtaposition on a same stand (= of their addition), the ants went mostly to each single cue and very poorly to the added cues, a choice which was highly significant. Consequently, the ants did not add visual cues of different shapes. During the second experiment, the ants were trained to two cues of different colors, i.e. to a black cue and to a yellow, green or orange one. Tested in front of each of the two single cues used during training and to their juxtaposition on a same stand (= to their addition), the ants visited far more often each single cue than the added cues, and this was statistically significant. It could thus be concluded that the ants did not add cues of different colors. In the course of the third experiment, the ants were trained to two cues of different sizes, i.e. to a large square and to a small one, a vertical rectangle or a horizontal rectangle, the area of which equaled respectively $1 / 4,1 / 2,1 / 2$ that of the large square. When confronted to each of the two single cues seen during training and to their juxtaposition on a same stand (= to their addition), the ants reacted mostly to each single cue and only very little to the added cues. This was highly significant. Thus, the ants did not add visual cues of different sizes. During the fourth experiment, the ants were trained to two cues differently located on their stand, i.e. highly or lowly located as well as located on the left or on the right of the stand. When tested in front of the two single differently located cues and of their juxtaposition on a same stand (= of the addition), the ants went far more often to the added 
cues than to each single one, what was highly significant. Consequently, the ants added identical cues differently located on a stand measuring $2 \mathrm{~cm} \times 2 \mathrm{~cm}$. At this stage of our study, it remained to define the maximum horizontal and vertical distance between cues for enabling ants to add them up. This was the aim of our two last works (see below).

3.5 Maximum Horizontal Distance Between Visual Cues Until Which Ants Mentally Add Them Up

Table 5. Defining the maximum horizontal distance between two visual cues beyond which the ants no longer add them up

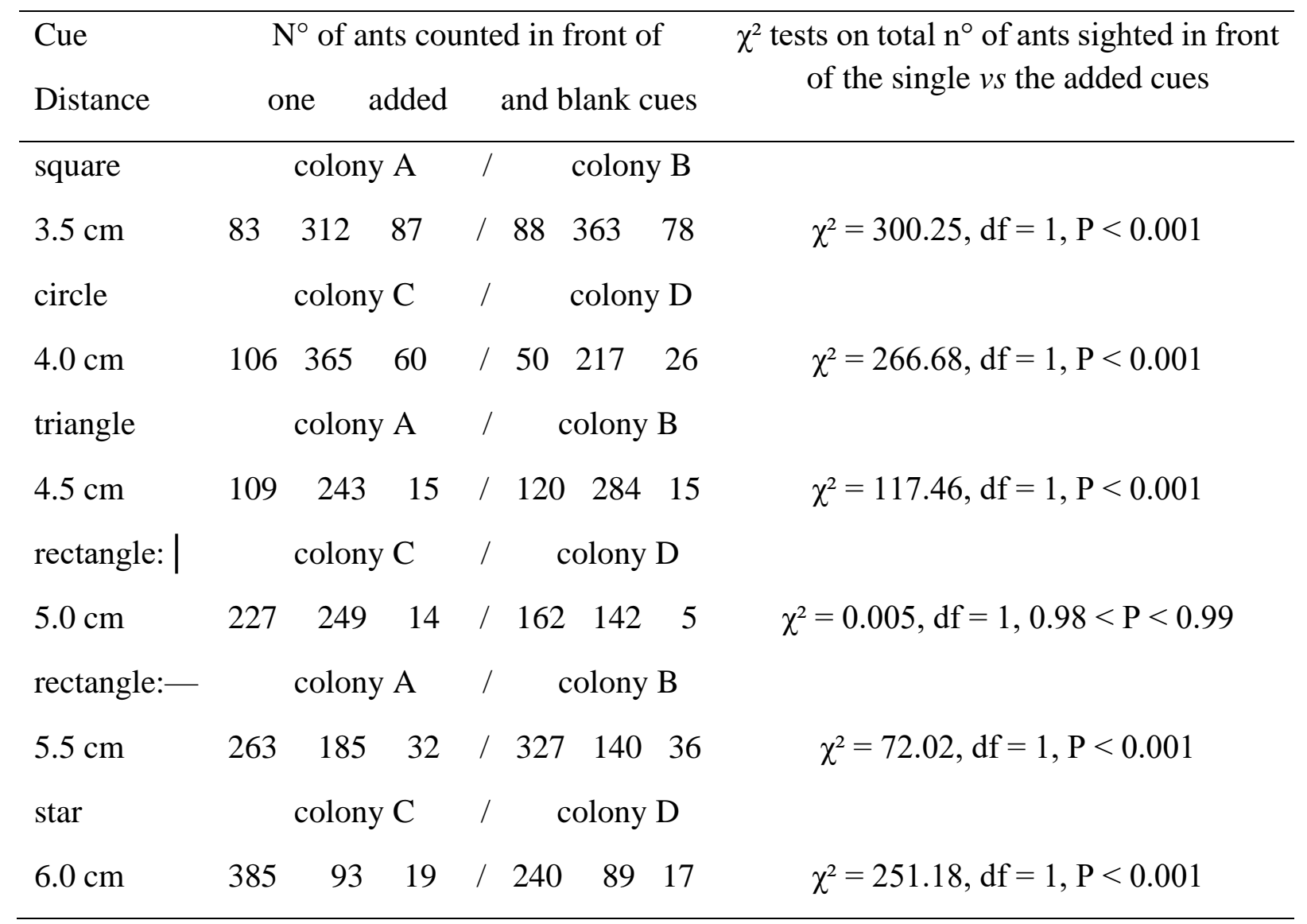

The critical distance equals thus $5 \mathrm{~cm}$.

Numerical results and statistical analysis are presented in Table 5 and photos of the experiments are shown in Figure 5. Six experiments were performed. Each time, the ants of two colonies were trained to two identical cues (a square, a circle, a triangle, a vertical rectangle, a horizontal rectangle, and a star for the experiments I to VI respectively) set from one another at a horizontal distance of $3.5 \mathrm{~cm}, 4.0 \mathrm{~cm}, 4.5 \mathrm{~cm}, 5.0 \mathrm{~cm}, 5.5 \mathrm{~cm}$ and $6.0 \mathrm{~cm}$, for the experiments I to VI respectively. Over their 72 training hours, the ants were tested six times in front of single cues identical to those presented during training, of two such added cues (= presented on the same stand) and of a blank stand. When the distance between the two cues presented during training equaled $3.5 \mathrm{~cm}, 4.0 \mathrm{~cm}, 4.5 \mathrm{~cm}$ (experiments I, II, III 


\section{Al Macrothink Institute ${ }^{T M}$}

respectively), the ants went statistically mostly to the added cues. When the distance between the two cues presented during training equaled $5.0 \mathrm{~cm}$ (experiment IV), the ants went nearly equally to the two added cues and to the single one. When the distance between the two cues presented during training equaled $5.5 \mathrm{~cm}$ or $6.0 \mathrm{~cm}$ (experiments $\mathrm{V}$ and VI respectively), the ants preferentially went to the single cue, thus no longer adding the cues. Consequently, 5.0 $\mathrm{cm}$ is the critical horizontal distance between visual cues until which $M$. sabuleti ants add up the cues and beyond which they no longer add them up but act such as they perceived the cues consecutively.

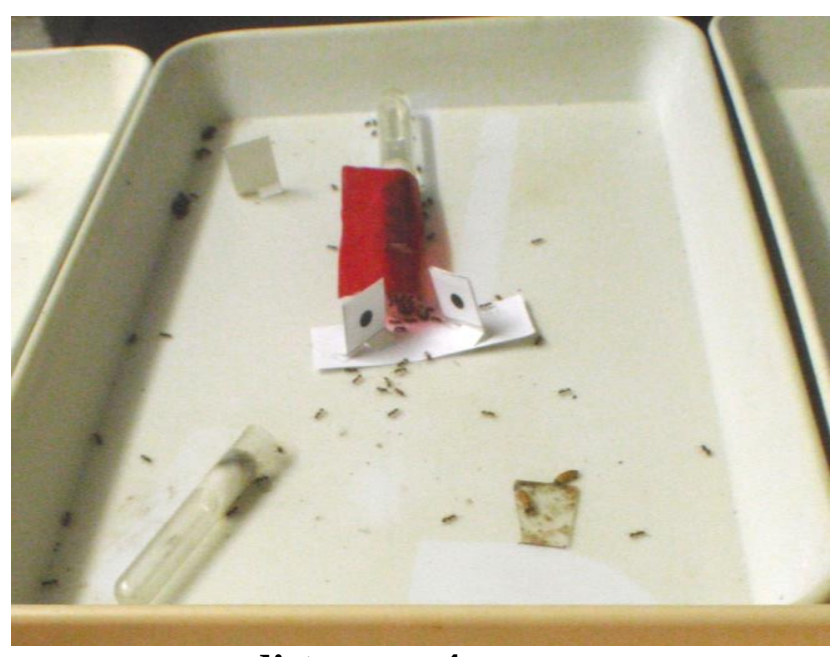

distance $=4 \mathrm{~cm}$

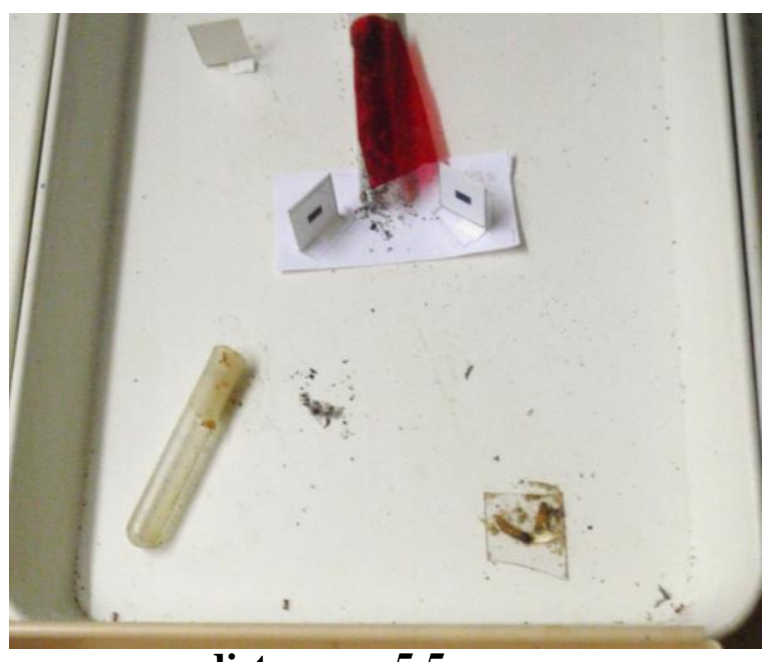

distance $=5.5 \mathrm{~cm}$
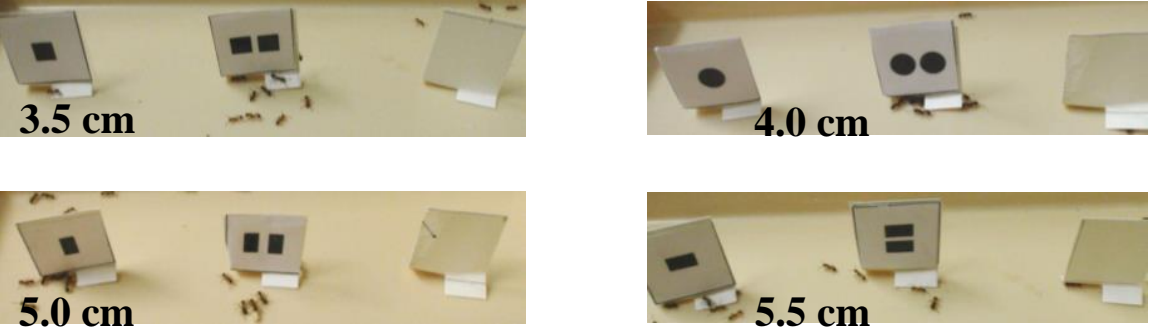
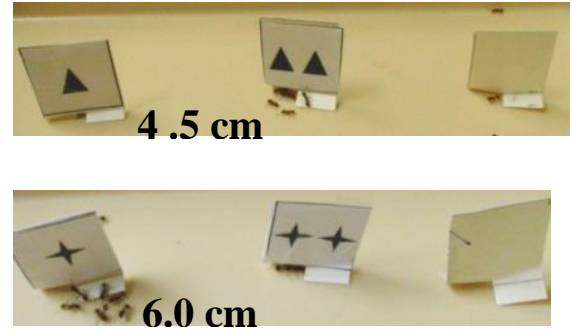

Figure 5. Some photos of experiments made to define the maximum horizontal distance between two visual cues beyond which the ants no longer add them up. Upper photos: two examples of ants' training. Lower photos: examples of ants' testing in front of a single cue, of two such added cues and of a blank cue, while the two single cues had been presented during training with a horizontal distance of $3.5,4.0,4.5,5.0,5.5$ or $6.0 \mathrm{~cm}$ between them. The ants added the cues which were presented at a distance of 3.5 to 4.5 from one another during training, equally reacted to the added and the single cue when the cues were set at a distance of $5.0 \mathrm{~cm}$ from one another during training, and no longer added the cues (= reacted to the single cue) when the distance between the cues was 5.5 and $6.0 \mathrm{~cm}$ during training. The researched maximum distance equals thus $5.0 \mathrm{~cm}$. 
3.6 Maximum Vertical Distance Between Visual Cues Until Which the Ants Mentally Add Them Up

It has been previously shown that the ants' sensitivity to a horizontal and a vertical change of orientation of a linear segment differed (Cammaerts, 2008). Therefore, the maximum vertical distance between visual cues still enabling the ants to mentally add them up may differ from the maximum horizontal distance. A last reported work aimed thus to define this potentially different vertical distance (see below).

Table 6. Defining the maximum vertical distance between two visual cues beyond which the ants no longer add them up

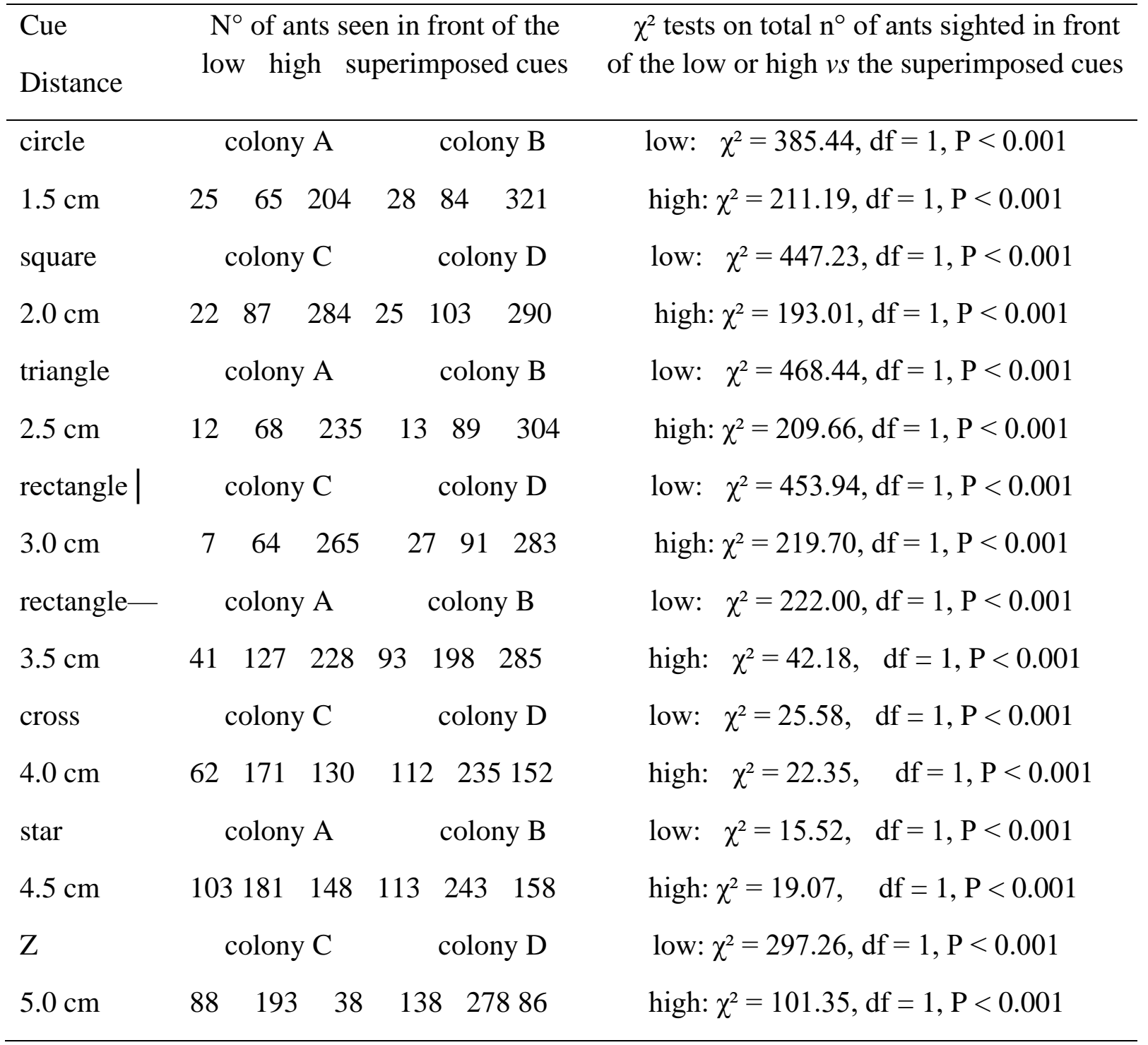

The critical distance equals thus $4 \mathrm{~cm}$.

Numerical results and statistics are given in Table 6 and photos are shown in Figure 6. Eight experiments were performed. For each of these experiments, the ants of two colonies were trained to two identical cues (a circle, a square, a triangle, a vertical rectangle, a horizontal rectangle, a cross, a star, a letter ' $Z$ ' for the experiments I to VIII respectively) set side by side 


\section{Macrothink}

near the nest entrance, one cue being lowly located (at a height of 1-3 mm), the other one being highly located, at a vertical distance from the lowly located cue of 1.5, 2.0, 2.5, 3.0, 3.5, $4.0,4.5,5.0 \mathrm{~cm}$ respectively for the experiments I to VIII. Over 72 training hours, the ants were tested in front of the lowly located cue, the highly located cue and the two superimposed cues, the height at which the cues had been presented during training being maintained. It was checked that the ants could perceive the most highly presented cue, and this pointed out a perfect agreement between the work in course and another previous one (Cammaerts, 2004). When the vertical distance between the two presented cues equaled 1.5 $\mathrm{cm}$ to $3.5 \mathrm{~cm}$ (experiments I to $\mathrm{V}$ respectively), the ants significantly went mostly towards the superimposed cues, adding thus mentally the two single cues. When the vertical distance between the two presented cues equaled $4.0 \mathrm{~cm}$ and $4.5 \mathrm{~cm}$ (experiments VI and VII), the ants significantly went mostly to the highly located cue and less often to the superimposed cues, thus no longer adding the cues, though they did not go more often to the lowly located cue than to the superimposed ones. When the vertical distance between the two presented cues equaled $5.0 \mathrm{~cm}$ (experiment VIII), the ants went more to the highly and the lowly located single cues than to the superimposed cues, thus not adding the two cues, and this was statistically significant. The researched vertical maximum distance between cues until which ants add up the cues equals thus $4 \mathrm{~cm}$. In addition, during each experiment, the ants better reacted to the highly than to the lowly located cue. In fact, due to the morphology of their eyes and the location of their eyes on their head, the ants better see what is above them than what is in front of them (Rachidi et al., 2008). 


\section{Macrothink}

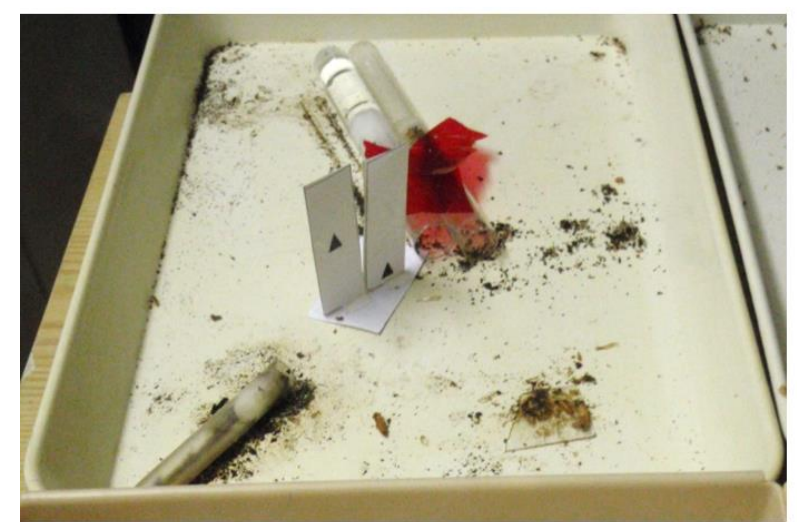

training to'two triangles-located at $\cdot 2.5 \cdot \mathrm{cm} \cdot$ from one another
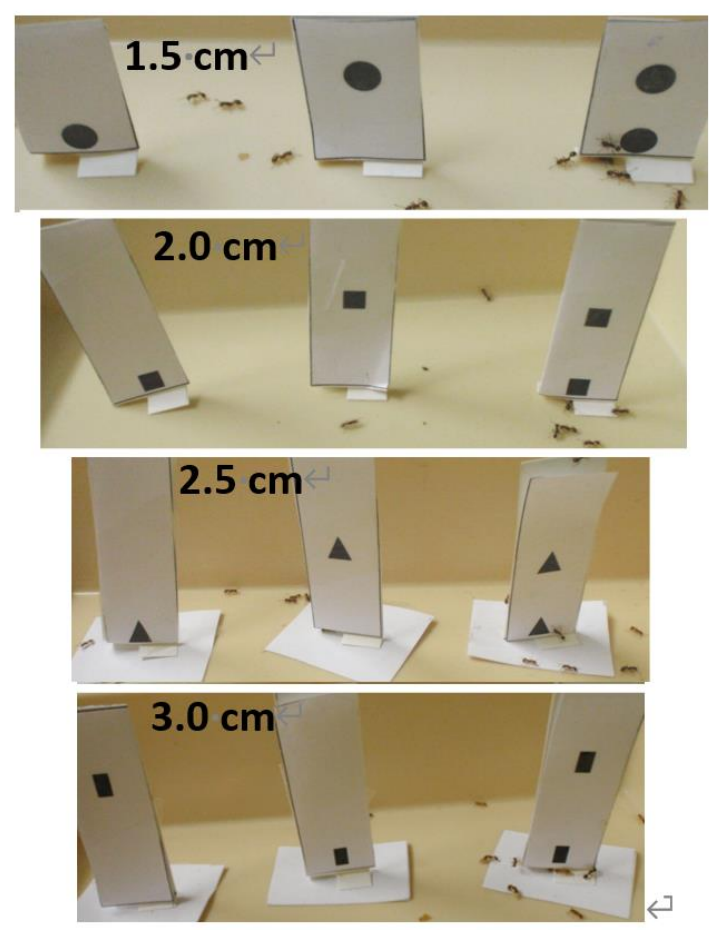

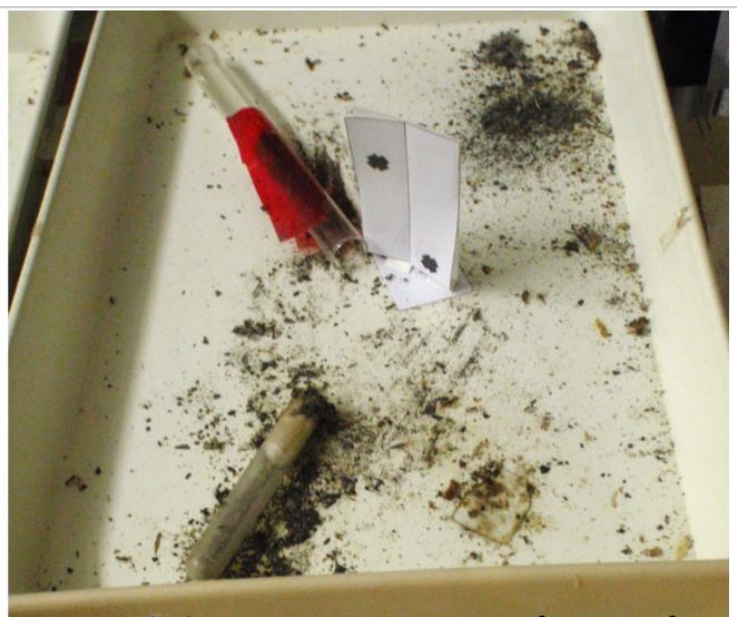

training to'two'crosses/located at·4.0.cm $\cdot$ from one another
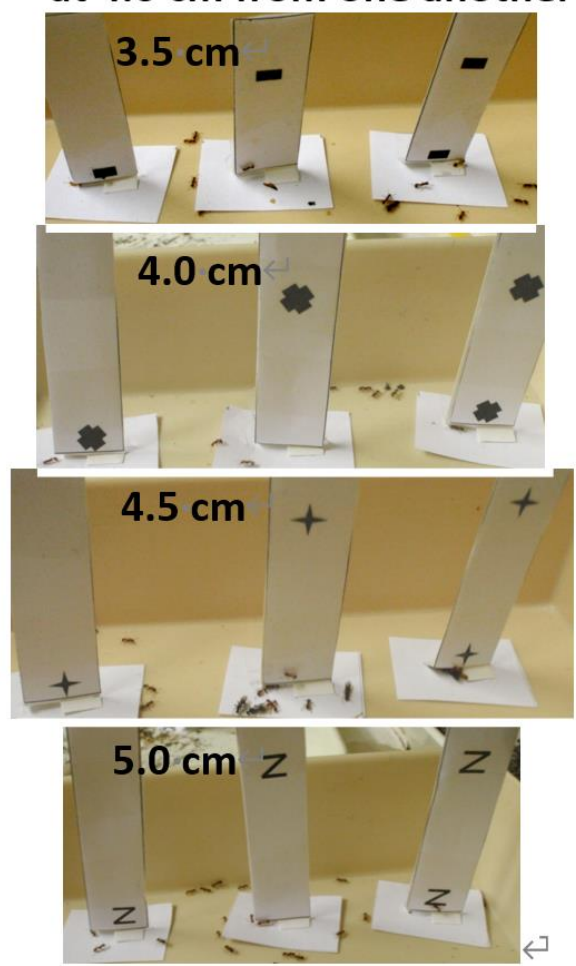

Figure 6. Some photos of the experiments made to define the maximum vertical distance between two visual cues beyond which $M$. sabuleti ants no longer add them up. Upper photos: two examples of ants' training. Lower photos: examples of ants' testing in front of each of the two single cues and of the two superimposed cues, the two single cues having been presented during training with a vertical distance between them equaling 1.5, 2.0, 2.5, 3.0, 3.5 or $5.0 \mathrm{~cm}$. The ants added the cues presented at a distance of 1.5 to $3.5 \mathrm{~cm}$ from one another, and no longer the cues presented at a distance of 4.0 to $5.0 \mathrm{~cm}$ from one another. The critical distance equals thus $4.0 \mathrm{~cm}$.

\section{Discusion}

We have thus shown that the workers of the ant $M$. sabuleti can expect the following element in an increasing or decreasing arithmetic or geometric sequence only when in presence of the 
sequence, and have defined the physical conditions enabling these ants to add up numbers of elements, i.e. the elements must be of the same shape, color and size, and located from one another at a distance not larger than $5 \mathrm{~cm}$ horizontally and $4 \mathrm{~cm}$ vertically. These findings enlarge our knowledge of the ants' cognitive abilities.

The here shown ants' expectative behavior about a sequence did not require complex thinking; it is simply issued from conditioning (associative learning), together with the sense of running time and numerosity ability (Lind, 2018; Enquist et al., 2016). In fact, these insects behave always staying at a concrete level, never reaching an abstract one. Also, let us remark that, when ants just count elements, they are not markedly affected by the characteristics of the elements to count (Cammaerts \& Cammaerts, 2020c). They take these characteristics into account only for adding elements.

The ants' behavior here observed could be useful for their daily life in the wild. Fore thinking future potential events is advantageous, as it prepares to face future events. It is advantageous to do so only when the environmental conditions remain (i.e., in the present experiments, when being in the presence of the sequence of elements) and not when these conditions no longer exist. Adding only identical elements and not different ones, as well as elements located rather near from one another and not those located far from each other, is exactly what is required for easily, correctly and rapidly navigating, going to food sites, and coming back to the nest.

Myrmica sabuleti ants may acquire the here revealed expectative behavior in the course of their second year of life, through experienced events, in the same way as they acquire, among others, temporal learning, expectation of the following food delivery, self recognition, and the notion of zero (Cammaerts \& Cammaerts, 2015c, 2015b, 2020b). The young ants do not yet detain these cognitive abilities. In fact, some of the ants' abilities are innate, e.g. having a left to right oriented number line (Cammaerts \& Cammaerts, 2020a), some ones are acquired through imprinting, e.g. knowing the appearance of the front face of their congeners, and other ones are learned in the presence of older congeners, e.g. alarm reaction and trail following (Cammaerts \& Cammaerts, 2015a). All this looks like what exists in vertebrates (birds, mammals) which have high-level cognitive abilities (Pearce, 2005).

Myrmica sabuleti ants see better what is highly located than what is lowly located. This is due to their eyes' morphology and the location of their eyes on the head (Rachidi et al., 2008). The limit of the ants' vertical visual perception depends on their subtended angle of vision. As an example, Myrmica ruginodis Nylander, 1846 workers have a smaller angle of vision than M. sabuleti workers (Cammaerts, 2004), and therefore can distinguish small luminous points located above them (Cammaerts, 2008). They nest under branches, use cues located in the canopy, and use celestial cues during the night (Cammaerts, 2012).

We have recently shown that the workers of the ant $M$. sabuleti can associate visual cues as well as odors with the time period of occurrence of these elements (Cammaerts \& Cammaerts, unpublished data). It may thus be possible that $M$. sabulet $i$ workers can also associate a given number of elements with its time period of occurrence. Also, these ants add numbers of elements when they see them simultaneously. What is the delay, i.e. the maximum time 
interval between the sight of two numbers (or numerosities), enabling these ants to still add them up? These two raised questions will be the aim of future research.

In the introduction section, we showed that M. sabuleti workers' numerosity abilities are in agreement with those observed in other animal species. Even more so, these abilities are found in humans at a much higher level. Humans also expect or try to expect what will occur in the future on the basis of previous experienced events, doing so for numerous topics, e.g. for money (probably the most concerned topic), work, holidays, health caring and travelling. Like ants, humans consider as a whole the elements whose characteristics do not differ and which are perceived simultaneously. As a matter of fact, some aspects of the ants' behavior are also present in other animal species, including humans, but in them, these capabilities reach a much higher level of complexity. Using ants as biological models allows studying these capabilities more easily, basically, rapidly, and with less ethical considerations.

\section{Conclusion}

The numerosity capabilities detained by the ant $M$. sabuleti have been studied through 16 works summarized in Cammaerts \& Cammaerts (2020d, e) and 6 more recent works summarized in this article (expectation of the next element in an arithmetic and geometric sequence; adding up elements when they are of the same kind and located from each other at maximally $5 \mathrm{~cm}$ horizontally and $4 \mathrm{~cm}$ vertically). Two questions remain to be resolved: can ants associate numbers of elements with their time period of occurrence, and what is the maximum temporal delay (i.e. the time interval) between the ants' perception of two numbers enabling them to still add up these numbers? On the basis of what we know about the ants' biology and abilities, and even if a priori their skills seem very efficient, the ants always behave, react, and learn at a concrete level, i.e. they never reach abstraction. The ants' abilities we studied appear to have the characteristics required for efficiently performing social tasks such as navigating, collecting food, and relocating the nest. From our studies it appears that ants are good biological models for examining cognitive abilities at low cost, with large samples, and with little ethical consideration.

\section{Conflict of interest}

We affirm having not conflict of interest concerning the topic here presented.

\section{References}

Agrillo, C., Dadda, M., Serena, G., \& Bisazza, A. (2008). Do fish count? Spontaneous discrimination of quantity in female mosquitofish. Animal Cognition, 11(3), 495-503. https://doi.org/10.1007/s10071-008-0140-9

Beugnon, G., \& Macquart, D. (2016) Sequential learning of relative size by the neotropical ant Gigantiops destructor. Journal of Comparative Physiology. A, 202, 287-296. https://doi.org/10.1007/s00359-016-1075-2

Cammaerts, M. C. (2004). Some characteristics of the visual perception of the ant Myrmica sabuleti. Physiological Entomology, 29, 472-482.

https://doi.org/10.1111/j.0307-6962.2004.00419.x 


\section{Macrothink}

Cammaerts, M. C. (2008) Visual discrimination of cues differing as for their number of elements, their shape or their orientation, by the ant Myrmica sabuleti. Biologia, 63, 1169-1180. https://doi.org/10.2478/s11756-008-0172-2

Cammaerts, M. C. (2012). The visual perception of the ant Myrmica ruginodis (Hymenoptera - Formicidae). Biologia, 67,1165-1174. https://doi.org/10.2478/s11756-012-0112-z

Cammaerts, M. C., \& Cammaerts, R. (2015a). Ontogenesis of ants' cognitive abilities (Hymenoptera, Formicidae). Advances Studies in Biology, 7, 335-348 + synopsis: 349-350. https://doi.org/10.12988/asb.2015.5424

Cammaerts, M. C., \& Cammaerts, R. (2015b). Are ants (Hymenoptera, Formicidae) capable of self recognition? Journal of Sciences, 5(7), 521-532.

https://doi.org/10.12988/asb.2015.5424

Cammaerts, M. C., \& Cammaerts, R. (2015c). Expectative behavior can be acquired by ants in the course of their life. Trends in Entomology, 11, 73-83.

http://www.researchtrends.net>tia>title

Cammaerts, M. C., \& Cammaerts, R. (2016a). Spatial expectation of food location in an ant on basis of previous food locations (Hymenoptera, Formicidae). Journal of Ethology, 35(1), 9. https://doi.org/10.1007/s10164-016-0494-4

Cammaerts, M. C., \& Cammaerts, R. (2016b). Ants can expect the time of an event on basis of previous experiences. ISRN Entomology. Article ID 9473128. 9 pages. https://doi.org/10.1155/2016/9473128

Cammaerts, M. C., \& Cammaerts, R. (2019a). Ants' capability of adding numbers of identical elements. International Journal of Biology, 11(3), 25-36.

https://doi.org/10.5539/ijb.v11n3p25

Cammaerts, M. C., \& Cammaerts R. (2019b). Ants fail to add numbers of same elements seen consecutively. International Journal of Biology, 11(3), 37-48.

https://doi.org/10.5539/ijb.v11n3p37

Cammaerts, M. C., \& Cammaerts, R. (2020a). Young ants already possess a number line. International Journal of Biology, 12(2), 1-12. https://doi.org/10.5539/ijb.v12n2p1

Cammaerts, M. C., \& Cammaerts, R. (2020b). Ants acquire the notion of zero through experiences. International Journal of Biology, 12(2), 13-25.

https://doi.org/10.5539/ijb.v12n2p13

Cammaerts, M. C., \& Cammaerts, R. (2020c). Influence of shape, color, size and relative position of elements on their counting by an ant. International Journal of Biology, 12(2), 26-40. https://doi.org/10.5539/ijb.v12n2p26

Cammaerts, M. C., \& Cammaerts, R. (2020d). Ants'numerosity ability defined in nine studies. Journal of Biology and Life Sciences, 11(1), 121-142.

https://doi.org/10.5296/jbls.v11i1.16278 


\section{MIMacrothink}

Journal of Biology and Life Science ISSN 2157-6076 2022, Vol. 13, No. 1

Cammaerts, M. C., \& Cammaerts, R. (2020e). Summary of seven more studies on numerosity abilities in an ant, four of them relating to human competence. Journal of Biology and Life Sciences. 11 (2). 296-326. https://doi.org/10.5296/jbls.v11i2.17892

Cammaerts, M. C., \& Cammaerts, R. (2021a). Ants can anticipate the following quantity in an arithmetic sequence. Behavioral Sciences 11(2), 18, 13p.

https://doi.org/10.3390/bs11020018

Cammaerts, M. C., \& Cammaerts, R. (2021b). Ants can anticipatively and correctly increment the last quantity of a learned arithmetic sequence. International Journal of Biology. 13(1), 16-25. https://doi.org/10.5539/ijb.v13n1p16

Cammaerts, M. C., \& Cammaerts, R. (2021c). Ants can expect the size of the next element in a geometric sequence of increasing or decreasing shapes, only if this sequence is present. Internal Journal of Biology, 13(2), 37-48. https://doi.org/10.5539/ijb.v13n2p37

Cammaerts, M. C., \& Cammaerts, R. (2021d). Reaction of ants to the simultaneous sight of two identical or different cues. Trends in Entomology, 17, 21-24.

http://www.researchtrends.net>tia>title

Cammaerts, M. C., \& Cammaerts, R. (2021e). Critical distance between two identical visual cues allowing their mental addition by an ant. Trends in Entomology, 17, 43-56.

http://www.researchtrends.net>tia>title

Cammaerts, M. C., \& Cammaerts, R. (2021f). Critical vertical distance between two visual cues for allowing ants to mentally add them. Trends in Entomology, 17, 77-80.

http://www.researchtrends.net>tia>title

Clayton, N. S., \& Dickinson, A. (1998). Episodic-like memory during cache recovery by scrub jays. Nature, 395, 272-274. https://doi.org/10.1038/26216

Collett, T. S., Fry, S. N., \& Wehner, R. (1993). Sequence learning by honeybees. Journal of Comparative Physiology A., 172, 693-706. https://doi.org/10.1007/BF00195395

Correia, S. P. C., Dickinson, A., \& Clayton, N. S. (2007). Western scrub-jays anticipate future needs independently of their current motivational state. Current Biology, 17, 856-861. https://doi.org/10.1016/j.cub.2007.03.063

Enquist, M., Lind, J., \& Ghirlanda, S. (2016). The power of associative learning and the ontogeny of optimal behaviour. Royal Society of Open Science, 3, 160734. https://doi.org/10.1098/rsos.160734

Flombaum, J. I., Junge, J. A., \& Hauser, M. D. (2005). Rhesus monkeys (Macaca mulatta) spontaneously compute addition operations over large numbers. Cognition, 97, 315-325. https://doi.org/10.1016/j.cognition.2004.09.004

Garland, A., \& Low, J. (2014). Addition and subtraction in wild New Zealand robins. Behavioural Processes, 109, 103-110. https://doi.org/10.1016/j.beproc.2014.08.022

Howard, S. R., Avarguès-Weber, A., Garcia, J., \& Dyer, A. G. (2017). Free-flying honeybees 
extrapolate relational size rules to sort successively visited artificial flowers in a realistic foraging situation. Animal Cognition, 20(4), 627-638.

https://doi.org/10.1007/s10071-017-1086-6

Howard, S. R., Avarguès-Weber, A., Garcia, J. E., Greentree, A. D., \& Dyer, A. G. (2019). Numerical cognition in honeybees enables addition and subtraction. Cognitive Neuroscience, 5, 1-6. https://doi.org/10.1126/sciadv.aav0961

Hunt, S., Low, J., \& Burns, K. (2008). Adaptive numerical competency in a food-hoarding songbird. Proceedings of the Royal Society B: Biological Sciences, 275(1649), 2373-2379. https://doi.org/10.1098/rspb.2008.0702

Jozet-Alves, C. (2012). R29: les animaux se projettent-ils dans le temps? - Regards de la Société française d'écologie et d'évolution (sfe $\left.e^{2}\right) .8 \mathrm{March}$.

sfecologie.org/regard/r29-c-jozet-alves/

Kershenbaum, A., Blumstein, D. T., Roch, M. A., Akcay, C., Backus, G., Bee, M. A., \& al. (2014). Acoustic sequences in non-human animals. Biological Reviews, 92, 13-52. https://doi.org/10.1111/brv.12160

Lind, J. (2018). What can associative learning do for planning? Royal Society of Open Sciences, 5, 180778. https://doi.org/10.1098/rsos.180778

Osvath, M., \& Osvath, H. (2008). Chimpanzee (Pan troglodytes) and orangutan (Pongo abelii) forethought: Self-control and pre-experience in the face of future tool use. Animal Cognition, 11, 661-674. https://doi.org/10.1007/s10071-008-0157-0

Pearce, J. M. (2008). Animal learning and cognition. Psychology Press, Taylor and Francis Group, USA, Canada. pp 419.

Pepperberg, I. M., \& Gordon, J. D. (2005). Number comprehension by a grey parrot (Psittacus erithacus), including a zero-like concept. Journal of Comparative Psychology, 119(2), 197-209. https://doi.org/10.1037/0735-7036.119.2.197

Raby, C. R., Alexis, D. M., Dickinson, A., \& Clayton, N. S. (2007). Planning for the future by western scrub-jays. Nature, 445, 919-921. https://doi.org/10.1038/nature05575

Rachidi, Z., Cammaerts, M. C., \& Debeir, O. (2008). Morphometric study of the eye of three species of Myrmica (Formicidae). Belgian Journal of Entomology, 10, 81-91. http://www.srbe-kbve.be>files>BJE>BJE2008

Range, F., Jenikejew, J., Schröder, I., \& Virányi, Z. (2014). Difference in quantity discrimination in dogs and wolves. Frontiers in Psychology, 5, 1299. https://doi.org/10.3389/fpsyg.2014.01299

Rose, G. J. (2018). The numerical abilities of anurans and their neural correlates: insights from neuroethological studies of acoustic communication. Philosophical Transactions of the Royal Society B: Biological Sciences, 373. http://doi.org/10.1098/rstb.2016.0512

Rugani, R., Fontanari, L., Simoni, E., Regolin, L., \& Vallortigara, G. (2009). Arithmetic in 


\section{Macrothink}

newborn chicks. Proceedings of the Royal Society of London B, 276, 2451-2460 https://doi.org/10.1098/rspb.2009.0044

Schwing, R., Weber, S., \& Bugnyar, T. (2017). Kea (Nestor notabilis) decide early when to wait in food exchange task. Journal of Comparative Psychology, 131, 269-276. https://doi.org/10.1037/com0000086

Siegel, S., \& Castellan, N. J. (1988). Nonparametric statistics for the behavioural sciences. McGraw-Hill. Singapore.

Suddendorf, T., Addis, D. R., \& Corballis, M. C. (2009). Mental time travel and the shaping of the human mind. Philosophical Transactions of the Royal Society B, 364, 1317-1324. https://doi.org/10.1098/rstb.2008.0301

Woodruff, G., \& Premack, D. (1981). Primative [sic] mathematical concepts in the chimpanzee: proportionality and numerosity. Nature, 293(5833), 568-570. https://doi.org/10.1038/293568a0

\section{Copyright Disclaimer}

Copyright for this article is retained by the author(s), with first publication rights granted to the journal.

This is an open-access article distributed under the terms and conditions of the Creative Commons Attribution license (http://creativecommons.org/licenses/by/4.0/). 